\title{
6. Expanding Community Healing and Reconciliation through Therapeutic Art
}

AINSLEE WINTER

\section{Abstract}

The intent of this chapter is to determine the extent to which therapeutic art provides sufficient evidence to support healing and reconciliation. This will be explored by contemplating art as a mechanism for healing, both for the individual and for the larger community. The chapter will refer throughout to the prayer flag art experience that took place during the Tikkun Youth Project, as it aligns with the concepts of healing and reconciliation. The chapter will investigate the use of art as a means of collecting data and the use art as a form of research. Personal experiences, scholarly articles, and professional case studies will be utilized to support the hypothesis regarding the use of art as a means of healing and reconciliation.

Key words: Art therapy, Healing, Youth

I will begin my chapter with a short anecdote. I have always had great interest in human connection, empathy, and healing, right from when I was a young child. Growing up, I was surrounded by paintings and creativity but was unaware of its expansive capacity. My mother graduated from the Fine Arts program at the University of Windsor but did not pursue a career in the field. She has experienced significant loss throughout her life, and it is during these times that she delves into an intense art-making process. I have witnessed her go through life-transforming experiences and have seen her use her paintings as a form of coping, reflection, and self-discovery. She describes this process as a learning experience that allows emotions and reactions to come forward in a healthy way. She describes painting as a way 
to nurture her soul, take accountability for herself, and provide herself with the space to grieve, let go, and move forward. She finds joy and peace in this process.

After witnessing this process for my mother, I have come to realize she has been a model for me and for what I am able to share with others. I graduated with a BA (Hons) in Psychology and the Visual Arts, completed graduate studies for Art Therapy, and currently act as a professional art therapist. During my education, my understanding of how art can be used as a tool to enhance the healing processes began to expand. As I traveled around the world, I noticed other people using art as a form of healing, and I recognized that art was used historically as a means of healing and creating social change. I developed a clear understanding that art could be a form of healing and reconciliation, as it is deeply rooted within many different cultures. Some historical and cultural forms of healing through the arts will be described later in the chapter.

I have been involved with individuals from different cultures and backgrounds in a variety of projects that focus on building connections and finding meaning through art. The Tikkun Youth Project involved individuals from a variety of countries with different languages, cultures, and traditions.

Because art cuts across language barriers, it can reach vast populations. People can interact with what they see which elicits a physiological response. Art is a form of expression that expands the healing potential despite unique cultural and language differences. I have used therapeutic art with Syrian refugees who had moved to Windsor, Ontario shortly before my involvement with them. The goal of the art therapy program, which was made possible by Dr. Annette Dufresne of New Beginnings and the Multicultural Council, was to create a community and help refugees settle in and adapt to Canada. A second program, the Global Art Project for Peace, employed art-making to help individuals heal from the effects of trauma. The refugees' artwork emphasized a greater sense of connectedness, a form of expression (hope, dreams, interests), their spiritual traditions, and showed their vision of a more peaceful community.

The rest of this chapter will explore the variety of personal and professional events that link me to this profound question: Does therapeutic art provide sufficient research to support healing and reconciliation for individuals and the wider community? This chapter will explain how art is a healing modality for individuals and for whole communities. It will explore the ways in which art-making can be a form of data collection and will 
expand upon research methods that support this healing modality. Connections to the Tikkun Youth Project will be threaded throughout the chapter, as it provides an example of healing and reconciliation through therapeutic art.

Art can be seen as an opening, a form of expansion, and a safe place to discover the inner-workings of who we are and how we interact with our surroundings. The acknowledgment that art encompasses such depth and offers such an insight into one's psyche is a source of inspiration and motivation that support the transformation and healing of individuals and communities. I hope that this chapter will offer insight, expanded knowledge, and personal narratives that will continue to inspire and influence the reader.

\section{Art as Healing for the Individual}

The act of art-making is a transformative process that facilitates healing and leaves an impression on both the individual and the community. The process of creating art can "provide an opportunity to reformulate overwhelming emotional reactivity into a semblance of ordered thought" (Kaplan, 2007, p. 182). Individuals who have experienced trauma gain a sense of control as they externalize their overwhelming emotions through writing or artmaking (Kaplan, 2007). The art-making process can provide relief for the individual who may have been dissociating from the trauma as a form of protection and self-preservation (Kaplan, 2007). However, it is imperative that these vulnerable people feel safe when they are working with overwhelming emotions. When they do feel safe, their continued work of "self-expression and interpersonal connection within the creative and therapeutic process can offer a means of strengthening the Self" (Kaplan, 2007, p. 188).

\section{Devon's Story}

As an art therapist, I have worked with a variety of different populations, including high-risk youth. I worked with one adolescent male who was 
passionate about and driven to create birdhouses. I will refer to this client by the pseudonym Devon. Devon described his plans to care for birds by giving them shelter, water, and food. He was upset by having previously witnessed a bird that was injured and abandoned.

In his reflections, Devon connected his own story to the story of the injured bird. Devon had experienced a physically traumatic event; he could relate to the pain the bird was experiencing and had compassion for it. He did not want it to feel abandoned like he had felt in the past. Devon had come from an unstable environment where his basic needs were at times neglected.

The process of creating birdhouses was Devon's way of bringing stability and healing to these aspects of his own life. The act of making birdhouses served to open Devon up to major themes in his life that needed healing and support, such as insecurity, lack of stability, vulnerability, and fear. Artmaking enabled Devon to have a sense of control as he cared for the parts of his life that needed the most attention and healing. It also provided useful information that was critical for getting Devon more support. In his case, through art-making Devon was better able to identify his future needs and become an active participant in his own healing process.

\section{Healing Youth Through Therapeutic Art}

Therapeutic art can be particularly beneficial for the adolescent population. Art as a means of expression can be extremely useful for many youth who resist traditional forms of therapy and support. As these young people evolve from childhood and the state of play associated with it and become more reluctant to seek traditional help, art acts as a less invasive way for them to start the healing process (Briks, 2007). Youth facing challenges find that it is safe for them to use art as a healthy way to express their emotional world and discover their inner resources (Block, Harris, \& Laing, 2005).

Many youth coming for art therapy have a difficult time expressing their emotions verbally. In some cases, this difficulty may lead to them "acting out" if they have never been taught how to express their emotions in a healthy way. Scottish philosopher John Macmurray described humans as "embodied beings;" he explained that engaging in action is weighted with a similar importance as engaging in thought (McIntosh, 2015). This sense 
of embodiment emphasizes the human experience as a contained whole (parts working together simultaneously), and not as separate parts to a whole. Macmurray was arguing for the unity of mind (thought) and body (emotions), and he believed that action is motivated by our emotional desires and not solely by thought processes (McIntosh, 2015). Individuals are most efficient when mind and body work simultaneously. In art therapy, the act of art-making helps people connect with their emotions, which are often buried beneath the clutter and noise within the mind. Art acts as a bridge to connect thoughts and emotions, as well as an access point to further explore emotions that reside in the body that have been repressed. While creating (action), the mind is able to sense, perceive, and make judgment during this embodied practice. The Prayer Flag Art Experiential during the Tikkun Youth Symposium helped participants bridge emotional/felt senses within the body during the opening meditation, and forge connections with the mind through thought processes and reflection upon executing the art-making. This embodied practice is important as it addresses a more in-depth inquiry and reflection. Scholars have gathered evidence to prove that bridging both emotional expression and cognitive exploration support therapeutic change within a variety of modalities (Chilton, Gerber, Bechtel, Councill, Dreyer, \& Yingling, 2015).

\section{Sheeba's Story}

I worked with a client I will call Sheeba (pseudonym) who was experiencing intense emotions. She had a history of trauma and was getting in trouble for behaving violently towards other youth. To help this young person navigate her emotions, I used an art directive I call the Let Go and Transform activity. This activity has three steps. First, I directed Sheeba to create a scribble drawing using watercolour pencils that reflected her current emotional state. She used harsh red lines to represent her anger, soft blue lines to represent her sadness, and black for her confusion. This first step is typically created quickly (between 10 seconds and 2 minutes) and is used to externalize current emotions and validate the person's feelings. As all emotions have purpose, Sheeba and I took a moment to honour the emotions she had been holding.

The second step incorporates mindfulness and encourages the process of 
letting go. I had Sheeba dip a paint brush into water and begin to wash away the watercolour pencil marks while she connected with her breath. This step focuses on exploring the impermanence of emotions and increasing the awareness that emotions come and go. Typically, the line work from the first step will begin to fade and become gentler, but light imprints from the scribble drawing may remain (representing the scars that might exist from past experiences, but which have become a little less powerful).

The third step is optional and is only taken if the client has the emotional capacity, readiness, and willingness to do so. This step is called the transformation stage and provides an opportunity for the client to explore and find meaning within the artwork. This step focuses on connecting thought processes to emotions through body-based action techniques. I encouraged Sheeba to look at the new designs and altered line work with a fresh perspective. I then encouraged her to create a new image by adding more watercolour pencil and building on what was currently on the paper.

Some people can transform past experiences into opportunities to learn and grow. In the Let Go and Transform activity, the third step typically brings forth symbols that may provide the client with insight. Sheeba created an image that resembled a spider in a spider web. Together, she and I discussed the spider's powerful qualities, but also how the spider in its web reflects her feelings of being stuck. The symbol that Sheeba had created became a metaphor she connected with and could expand upon in a more comfortable way. Celebrated psychiatrist and psychoanalyst Carl Jung supported the importance and transformative potential of using an art image as a way of bringing denied aspects of the Self into conscious awareness to support the healing process (Hocoy, 2005). Video 1 demonstrates an example of all three steps of the Let Go and Transform art therapy directive. 


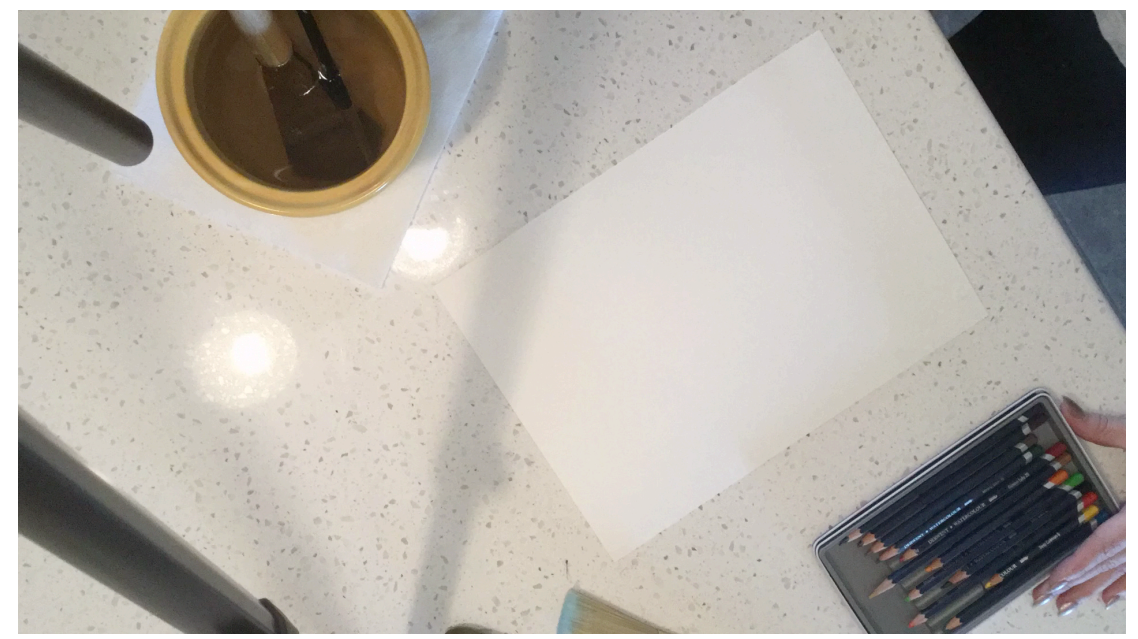

Still from video 1. Let Go and Transform time lapse.

\section{Art as Healing in Larger Communities}

The fact that traumatic reactions can extend well beyond the realm of the individual and into the larger community is an unfortunate truth. Many young people involved in the Tikkun Youth Symposium discussed much larger issues that affect larger communities including racism and segregation, violence and killing, and lack of compassion/understanding. Art has the capacity to facilitate large scale healing by addressing suffering, by building a community, and by developing a response with which people are able to interact continually. Art is an extension of many cultural and spiritual practices and has been shown to assist in healing populations that have experienced oppression (Archibald, Dewar, Reid, \& Stevens, 2010). 


\section{Sand Mandalas as a Healing Art Practice}

One healing art practice that has its origins in the $7^{\text {th }}$ century is Tibetan sand mandalas. Creating mandalas is a Buddhist practice used to reach individual enlightenment, liberate a sense of freedom, develop unconditional compassion, and access wisdom (Thorp, 2017). Buddhist monks use different coloured sand to create intricate designs. The designs may contain rituals, scripture, and meditative processes, and can represent up to 722 deities (Thorp, 2017). The practice of creating a mandala emphasizes the impermanence of life. Once the mandala is completed, it is ritualistically dismantled and released back into nature (Thorp, 2017).

Following the September 11, 2001 terrorist attack in the United States, the Dalai Lama (spiritual leader of Tibet and Tibetan Buddhism), instructed his monks to create a sand mandala at the former site of the New York Trade Center (Thorp, 2017). The goal was to protect the area from future attacks and to heal both the Earth and the people who were deeply hurt and distraught by the attack (Thorp, 2017). The act of creating this mandala is an example of the profound healing qualities encompassed in art that have been used for millennia as a part of culture and religion.

\section{Our Relationship with Art}

At times, art may be created to develop frameworks of viewing, experiencing, and connecting with the world at large (Potash \& Ho, 2011). The art becomes a third party that fosters relationships within diverse environments. Reconciliation is based on the need to bring together at least two parties that have strong differences. Art can help reunite both parties by facilitating a safe space for building relationships (Potash \& Ho, 2011). Being able to connect and engage with art as a third party allows space for individuals to make their own personal connections to the art. The interplay between the artwork and viewer, and the relationship they build, is what May (1975) describes as a creative encounter (Potash \& Ho, 2011). This connection can strengthen empathy and cultivate a sense of compassion. Through this powerful connection, the relationship between the original conflicting 
parties may become less hostile, more understanding, and on the path of reconciliation.

Art holds an energy that elicits a human response. The relationship between viewer and art is personal and the message the viewer receives from a piece of artwork may be significantly different than if the message were portrayed solely through words. Art provides an opening for individuals who may have been closed to beliefs and views that conflict with their own. Furthermore, art provides space in which the viewer can reflect and be curious rather than respond defensively and from an entrenched position.

Art can address social issues and create change on the individual and community levels. When individuals combine the process of making art with social action, they can develop a connection with something larger, which, in turn, can lead to many different experiences that will leave a positive impact on their lives. For youth to have a place where they feel included, empowered, and liberated, the community must be involved. Since adolescence is a time Erik Erikson (as cited in Marcia \& Josselson, 2013) identifies as a time to explore and define one's identity, it is beneficial for youth to be surrounded by positive role models and communities.

\section{The PhotoVoice Group Example}

The combination of art as healing and its capacity to create social change was captivated in a PhotoVoice group called Capture Compassion (Figure 1). PhotoVoice is a modality commonly used in community-based participatory research that showcases perspectives and increased awareness of people's social realities through photography (Suffla, Seedat, \& Bawa, 2015). It is often used with underrepresented (Warne, Snyder, \& Gadin, 2012) and diverse populations as a response to social justice issues (Suffla et al., 2015). The Tikkun Youth Symposium encompassed similar goals as Capture Compassion in relation to healing and creating social change. PhotoVoice is a modality that can be used in the future for youth interested in facilitating social change. The goal of Capture Compassion was to explore to what extent youth participation in an arts-based PhotoVoice group would contribute to their taking a "compassionate action approach" to developing a positive vision for themselves and/or their community. Youth were taught to use different tools and shown how to broaden their perspectives when approaching social 
injustices; they were shown how to create change through a compassionate action approach. This approach teaches individuals to transform any anger into motivated, purposeful, and non-destructive action; in this case, to alleviate social injustice (Ueda, 2013). Capture Compassion strengthened the PhotoVoice group's personal awareness through mindfulness and meditation, and through visual arts and photography. Belonging to the group strengthened its participants' sense of belonging, enhanced their willpower and self-worth, and provided a forum for self-development.

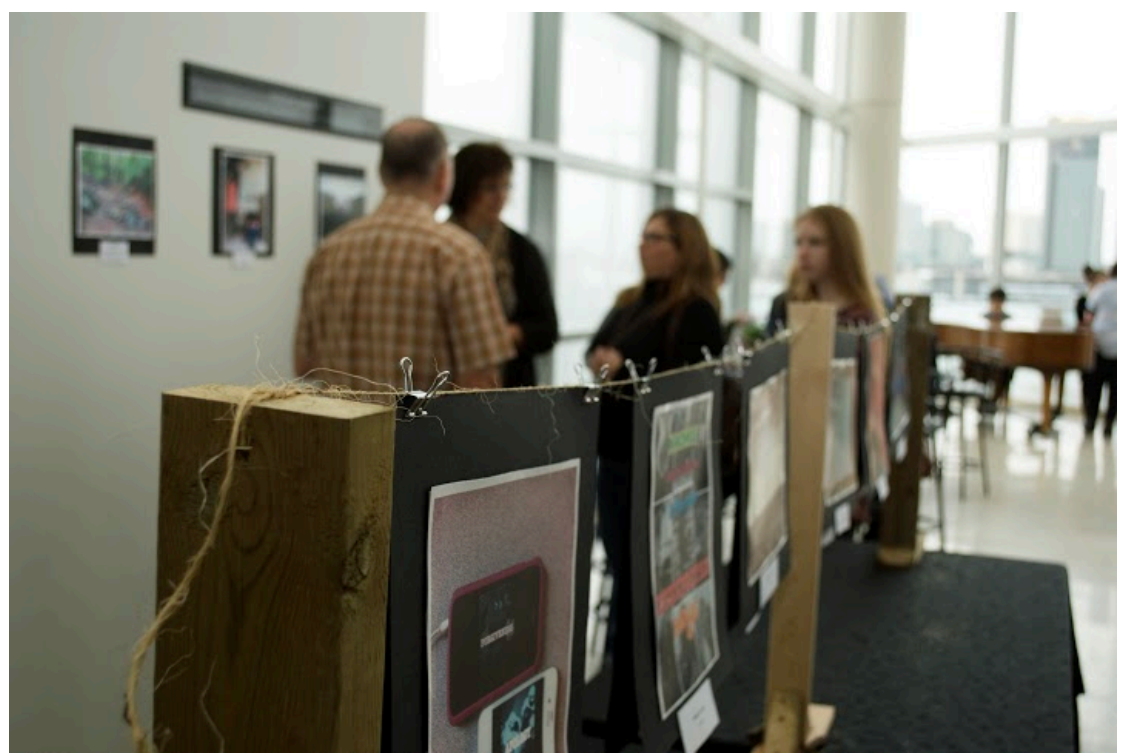

Figure 1. Capture Compassion youth PhotoVoice exhibition.

The art-making process enables communities to communicate their current needs (Potash \& Ho, 2011). People can use art to help them deal with environmental or cultural calamities. Linton (2017) discusses the benefits of implementing an art therapy group following the 2015 earthquake in Nepal. The group made their art from natural materials, which helped them reconnect with the earth - and supported their resilience and recovery following the natural disaster (Linton, 2017). 


\section{The Role of Art in Addressing Social Issues}

Art can also address social issues. For example, a school system may use art therapy to help students respond to racial discrimination or bullying. Art may address indigenous rights, gender discrimination, or poverty and living standards. Art may also be used outside of traditional settings (Kaplan, 2007).

In times of repression and civil unrest, art can depict the underrepresented and can reveal the unheard perspective (Bisschoff \& Van de Peer, 2013). In post-colonial times, art can express injustices that have happened in the past and bring an awareness of a traumatic history. Art tackles painful subjects and controversies, as is the case, for example, in the artwork related to genocide in Africa (Bisschoff \& Van de Peer, 2013). Art can bring forth healing, reconciliation, forgiveness, and a sense of justice to painful histories. Art can address truths that may have gone unnoticed or unrecorded. Art can be the first step in a move towards reconciliation. Once hidden voices or perspectives are revealed, it brings forth the opportunity to move forward with reconciliation.

\section{Tikkun Youth Project: Prayer Flag Art Directive and Data Collection}

Because of the strong link between art and reconciliation, a therapeutic art project was included in the Tikkun Youth Project. In this case, it was a series of prayer flags that were intended to remain at the University of Windsor so that students could interact with them and see their messages on a daily basis. As will be discussed in much greater detail below, the prayer flags share the vision and voice of youth with an extended audience, which further expands the mission of healing and reconciliation. The prayer flag project addresses social issues by incorporating the hopes and dreams of youth for the future. The project was hung outside a traditional setting to reach a wider audience and to help them develop their own response and process of reflection. The intention for the artwork is that it remain at the university to motivate continued interaction with each person who views it.

On April 5, 2017, the Tikkun Youth Project held an international youth symposium - a day of events to honour the culmination of the three years of 
facilitating youth-led social change initiatives. Individuals came to the prayer flag activity feeling somewhat drained as the day had been emotionally taxing. Youth shared personal stories of the injustices and hardships they had experienced that had inspired the social change work they are currently doing within their communities. Many also shared their healing journey and expressed gratitude for the group's support.

The day had begun with a high-energy and emotionally-moving Artnote. The Artnote shed light on individual narratives and brought a sense of connection to everyone. It provided an opportunity for those performing, and those witnessing, to have their hearts touched. The afternoon consisted of breakout sessions, where youth presented the research and work they have been advancing for an extended period of time. As a way to conclude the day of deep sharing and discovery, youth participants and people from the community were invited to respond through the prayer flag art directive. The art therapist gave the group a brief history of Tibetan prayer flags to give the art directive a cultural context and understanding. By providing context to the art directive, we encouraged a deepened purpose and meaning for those participating.

Prayer flags are an important part of Tibetan culture because they impart teachings from the Buddha (Barker, 2003). The origins of prayer flags date from thousands of years ago in Tibet, India, China, and Persia (Clark, 2002). Despite these flags being a Buddhist tradition, people from all backgrounds and beliefs are invited to participate. Flags are typically hung in holy places or across mountain plateaus with the belief that the wind will carry the prayers on the fluttering flags to bring blessings and healing to all beings that come in contact with the wind carrying the blessings (Barker, 2003). The prayer flag uses the power of the wind to carry and fill spaces with its healing potential (Clark, 2002). The prayer flags are a symbol of the movement towards a place of peace (Barker, 2003), which connects with the overarching themes of the Tikkun Youth Project.

The colours universally chosen for the prayer flags were utilized in the activity. The colours represent the five elements: space, air, water, fire, and earth. Historically, these colours (blue, white, green, red, yellow, respectively) were chosen to appease the elemental gods that were capable of causing great suffering through natural disasters (Clark, 2002). Before the activity began, the therapist shared the eight auspicious symbols that normally appear on traditional prayer flags with the participants, along with their meanings. The eight auspicious symbols include: umbrella or parasol 
(protection), golden fish (happiness), treasure vase (wishes fulfilled), lotus (purity and spiritual development), conch shell (enlightened teaching), endless knot (meditative mind or knowledge), victory banner (overcoming obstacles and choosing wisdom over ignorance), and the dharma wheel (spiritual or universal law) (Clark, 2002). Other, more traditional symbols are commonly represented on Tibetan prayer flags, but we limited the symbols in this activity to these eight. We did, however, encourage participants to create or use symbols with which they had a personal connection.

The art therapist led participants through a mindfulness visualization to help them become connected with themselves and participate in an embodied practice. This practice of embodiment assists individuals to become aware of sensations within their body, which can play a role in thought development. The mindfulness activity was designed to strengthen personal awareness and provide a period of time for self-reflection. We asked youth and community members to envision themselves as agents of change and to focus on one major theme, word, image, mantra, prayer, blessing, etc., that held deep importance to them.

After the mindfulness activity was completed, participants used different coloured markers to draw and write their vision on the flags. The therapist guided them to respond to the day's events by creating artwork that represented their own journey of healing and reconciliation, something that touched their heart that day, messages they would like to share, or their vision for the future. Participants spent about twenty minutes creating their flags. Some discussed their concepts with the people around them, but many entered a state of flow and became deeply focused in their own creative response.

Once the flags were completed, participants gathered at the front of the room to hang their flags together in harmony. Each was given a token to remember the impact and healing capabilities of prayer flags and their own vision as they continue on their journey. Everyone received a strip of paper that stated, "May all beings everywhere receive benefit and find happiness." This statement is derived from the Buddhist metta "loving-kindness" meditation. The prayer flags were hung during the final reception and remain hanging at the University of Windsor.

The prayer flag directive was an important component of the Tikkun Youth Project. Youth participants spent countless hours working towards the final day of presentations. Although many will continue to be agents of change within their communities following the Tikkun Youth Symposium, 
because the prayer flags remain at the university, they offer an experience of continued energy, intention, and impact. The culmination of collected vision, thoughts, prayers, and places of deep meaning, which the prayer flags represent, were left as an opportunity for continued impact.

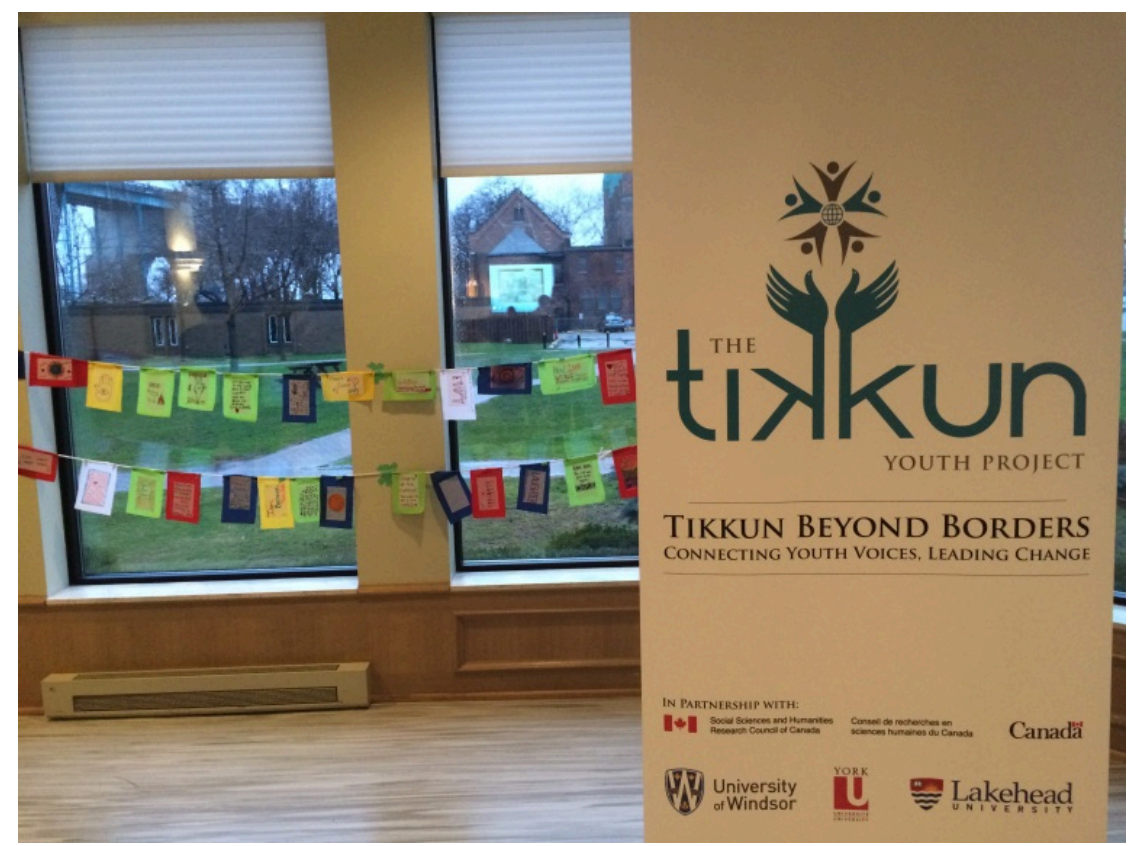

Figure 2. Tikkun Youth Project reception. 


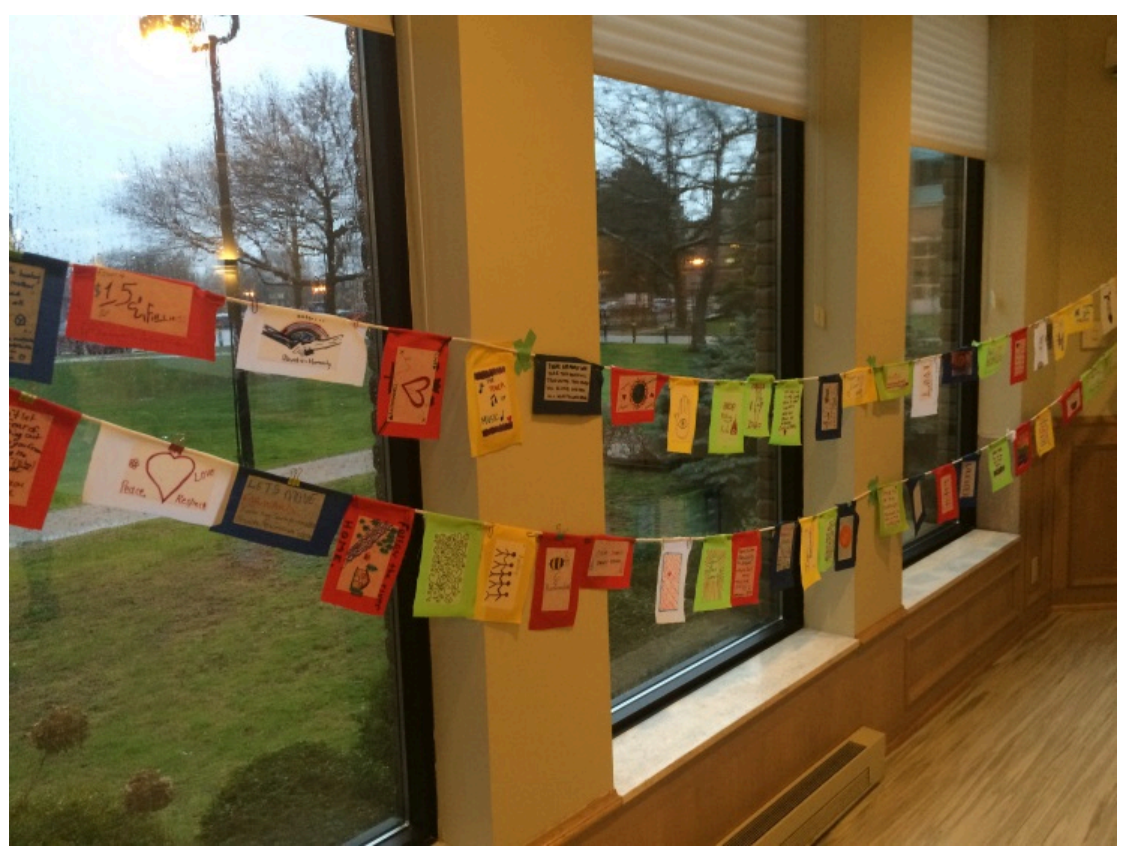

Figure 3. Hanging the prayer flags.

\section{Art as a Form of Data}

Through the therapeutic art-making process, research can be conducted using art as a form of data. Historically, there has been resistance to using art therapy to conduct research due to data collection challenges. These include whether or not to identify data as qualitative or quantitative, the question of ethics, etc. (Rubin, 2005). When setting out to use art to collect data, it is important to identify clear goals (Rubin, 2005). There are many ways to address and answer questions that inspire research, and it is up to the researcher to find an approach that best suits the needs of the question being asked (Rubin, 2005). It is essential that the researcher remain objective and, if possible, for the researcher to use an objective observation guide that is available to streamline this process (Rubin, 2005). In fact, we used this method to help support data collection in the prayer flag activity. Often art therapists will use self-report questionnaires, pre- and post-tests, or interviews (Snir \& Regev, 2014). The final art product is only part of 
the therapeutic experience. In the therapeutic setting, there is typically an emphasis on the process that may not be clear in the final artwork. Self-report questionnaires are able to focus on different themes that may have been present in the process of creating art but may not be evident in the final product. An example may be an individual feeling tight and tense within their body while initially creating, yet over time it turned into a fluid and relaxed image. The process acknowledges the journey of moving from discomfort and into fluidity (whereas, if only the artwork was being researched, one may only pick up on fluidity). Self-report questionnaires can be used to further analyze and create comparisons if appropriate for the research objective (Snir \& Regev, 2014). Snir and Regev (2014) describe the self-report questionnaires as useful for gaining more insight on clients' "perceptions, thoughts, preferences, desires, wishes, beliefs, habits, and behaviours" (p. 134).

Other research methods, used by Jennifer Laffier (2016) in a recent study, use art therapy as an intervention for psychological empowerment for bullying victims. To collect data, Laffier uses a qualitative content analysis - an approach that uses a data clustering method to identify core characteristics and meaning from artwork or written text. In Laffier's study, the artwork's components and factors were recorded chronologically and entered into an electronic data analysis system. In this way, artistic expression became a source of data collection. The entered data were further reviewed to uncover themes, and a cross-case comparison was developed to look at participant similarities and differences.

Often art therapists will use arts-based research methods because the artwork created is a source of inquiry to further examine major themes and concepts at play in the art-maker's life (Chilton et al., 2015). Although we did not collect and quantify the in-depth analysis processes or data from the Tikkun Youth Project, the prayer flag activity revealed ideas and major themes. The purpose of collecting these themes and ideas is to better understand the vision the youth created. The ideas collected from the youth artwork speak to the overall goal of repair and reconciliation which demonstrates how important it is to use art as a source of research and further inquiry.

Table 1

Major Ideas Described within the Prayer Flag Activity 


\begin{tabular}{ll}
\hline Idea & Occurrence \\
\hline Unity & 37 \\
Peace & 32 \\
Love & 32 \\
Healing & 28 \\
Action & 20 \\
\hline
\end{tabular}

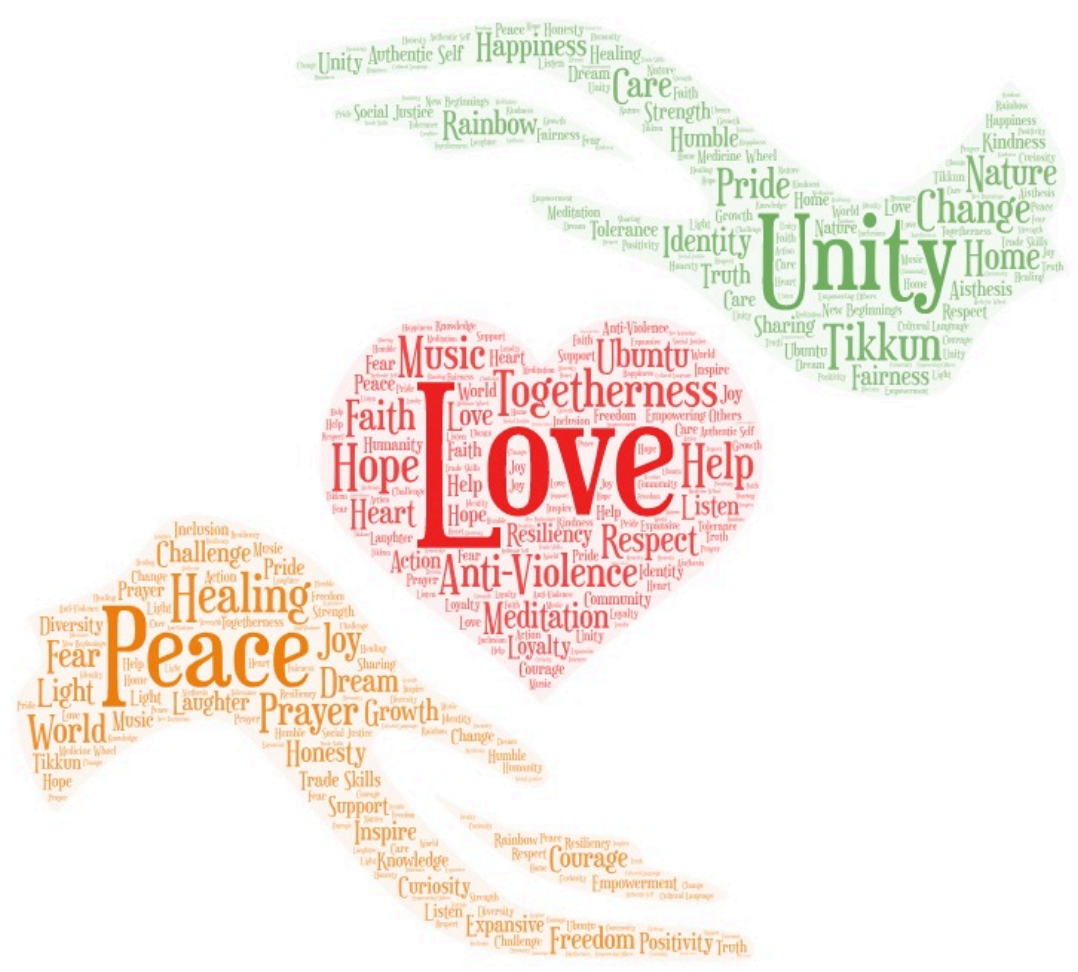

Figure 4. Prayer flag art directive word cloud.

Table 1 records the ideas expressed most commonly in the prayer flag activity: love, peace, unity, healing, and action. We compiled these themes after examining the words and images on 62 of the project's prayer flags. 
Figure 4 shows word clouds that capture all of the ideas expressed on the prayer flags.

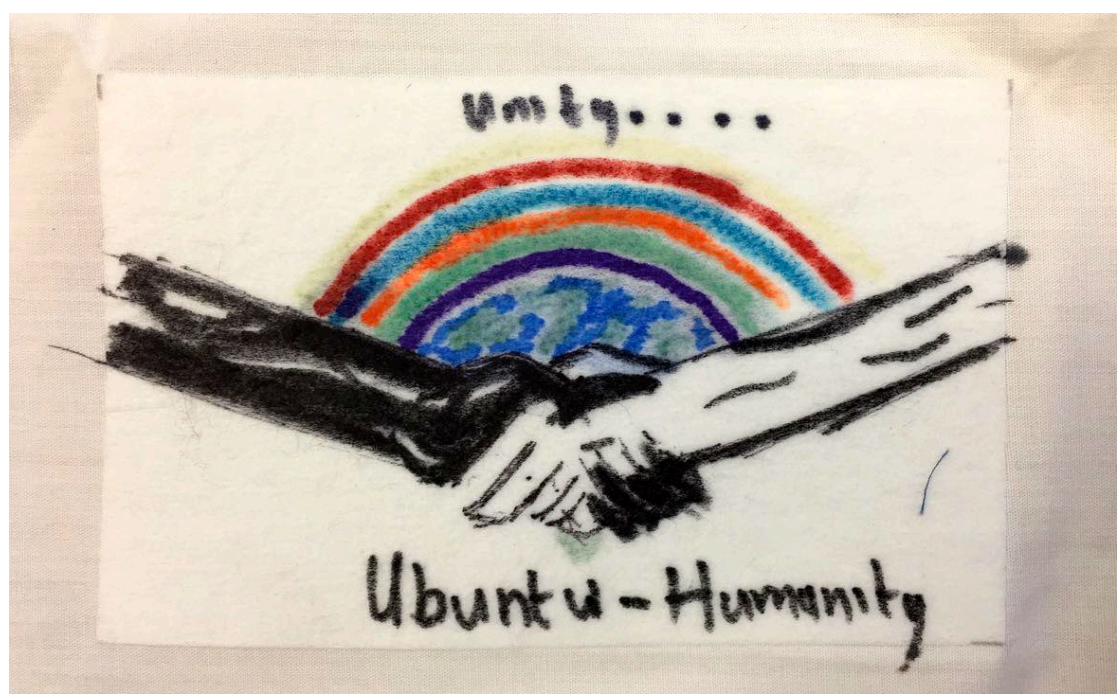

Figure 5. Example of youth vision of healing, reconciliation, and social change on prayer flags.

Figure 5 encapsulates many of the major themes collected during the prayer flag directive. Written across the top of this flag is "unity," and below are the words "ubuntu" and "humanity." Ubuntu is a South African concept that Archbishop Desmond Tutu describes this way: "A person is a person through other persons" (Bstan-'dzin-rgya-mtsho, Tutu, \& Abrams, 2016, p. 214). The concept speaks to the interconnectedness of human experience. Humanity is an intricate network and joyful experiences are possible thanks to the interactions within this network. In Figure 5, black and white hands come together - a symbol of reconciliation, togetherness, and forgiveness. This symbol is deeply meaningful for South Africa, which has a history of grave racial division. The flag's background - an image of the world surrounded by a rainbow - alludes to a future of peace, harmony, and healing. 


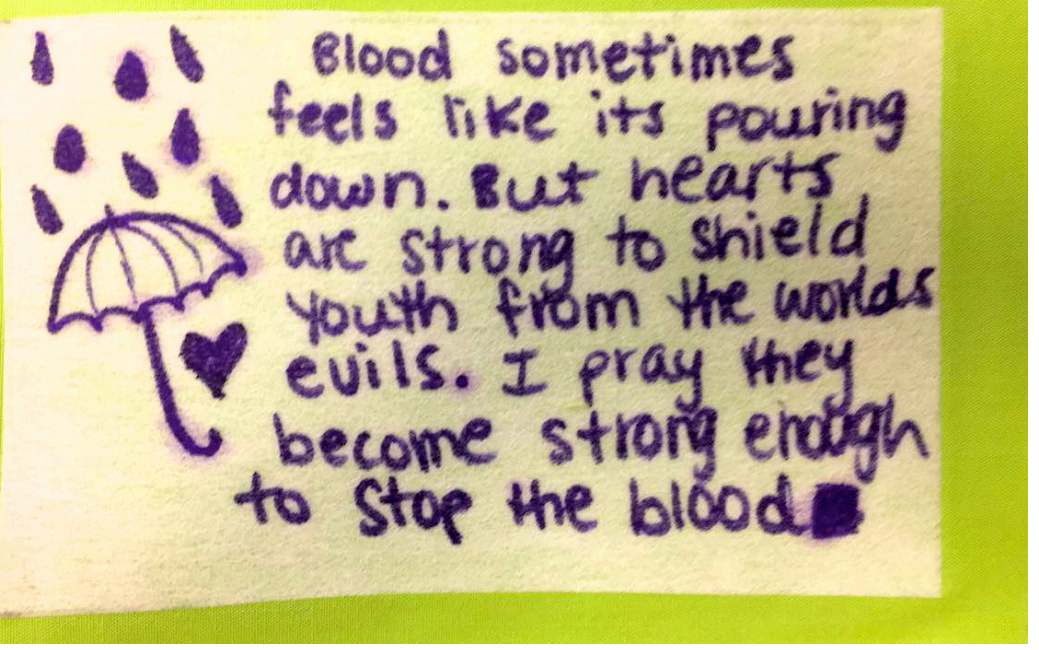

Figure 6. Example of youth vision of healing, reconciliation, and social change on prayer flags.

Figure 6 is a plea from a youth seeking protection from the darkness of the world and connecting with their spirituality through prayer. These powerful words acknowledge the violence, injustices, misfortunes, and suffering that people around the world experience. However, this flag also offers a sense of hope for the future. With the support of prayer, this artist hopes that youth will gain the strength to create changes and stop the injustices. This text is on the right and is beside an umbrella image on the left; the umbrella protects the artist's heart from the pain she feels around her. This image connects with the themes of action and healing: the artist is expressing the emotional state she is experiencing and is surrounding her heart with a boundary of protection. 


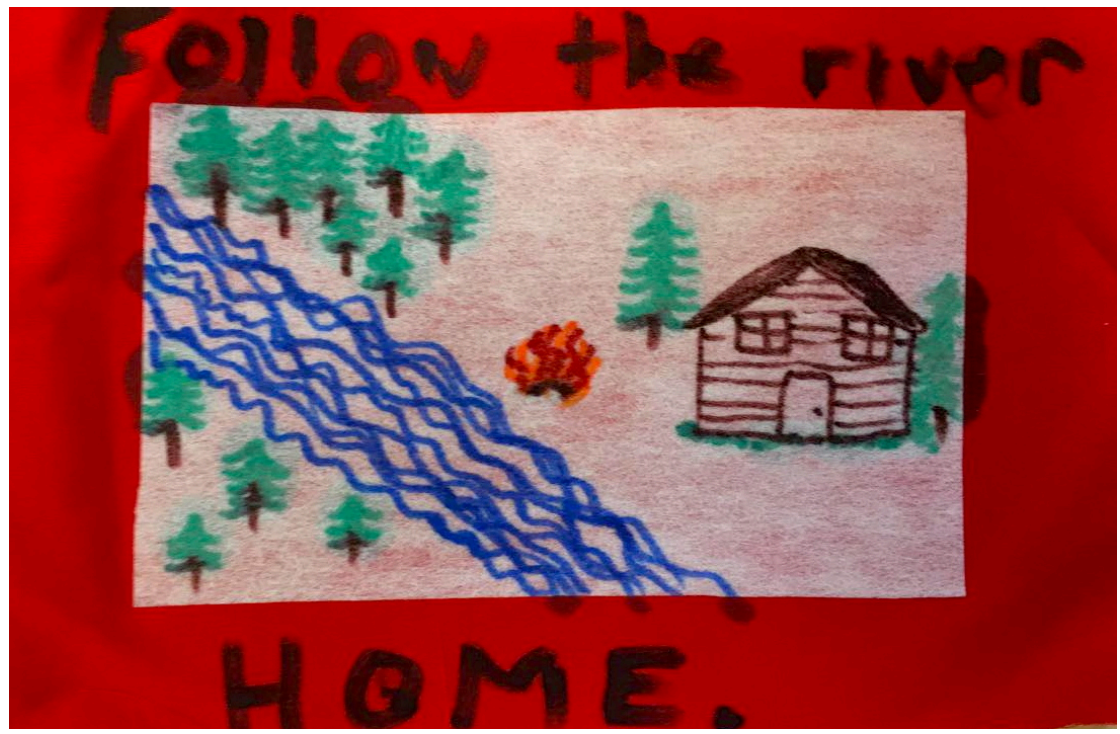

Figure 7. Example of youth vision of healing, reconciliation, and social change on prayer flags.

Figure 7 illustrates a longing for home and a connection to one's roots and may be associated with healing. Throughout the symposium, individuals shared stories of living many hours away from home to complete their schooling. This flag expresses feelings of peace, connection, and returning to a place of love.

\section{Conclusion and Recommendations for Future Research}

Therapeutic art-making can support healing, serve as a call to action, and be used as a form of data collection. Continued research into the role of therapeutic art and its capacity to bring forth healing and reconciliation would be beneficial. As the field of art therapy becomes more popular, it is likely that more concrete research will be conducted, and evidence 
discovered, that supports the use of art as a tool for reconciliation and healing.

This chapter has included examples of the ways that art can be used in healing, social action, and data collection. The prayer flag activity at the Tikkun Youth Symposium provides just one example of the great ability of the arts to incorporate healing, repair and reconciliation, and social action, while also providing a form of data. Other examples in this chapter support our findings, including the Capture Compassion PhotoVoice youth group, individual youth art therapy sessions, sand mandalas, Global Art Project for Peace (Syrian refugees), psychological empowerment for bullying victims, and art as social action for oppressed populations. It is inspiring to acknowledge the capacity and potential for future art projects and the benefits that are possible for individuals and communities from art-making. I am hopeful that I will continue to see passionate youth using art to drive their journeys of healing and social change.

\section{References}

Archibald, L., Dewar, J., Reid, C., \& Stevens, V. (2010). Rights of restoration.

Canadian Art Therapy Association Journal, 23(2), 2-17. doi:10.1080/ 08322473.2010.11432334

Barker, D. (2003). Tibetan prayer flags: Send your blessings on the breeze. Boston, MA: Connections Book Publishing Limited.

Bisschoff, L., \& Van de Peer, S. (2013). Art and trauma in Africa: Representations of reconciliation in music, visual arts, literature and film. New York, NY: I.B. Tauris \& Co. Ltd.

Block, D., Harris, T., \& Laing, S. (2005). Open studio process as a model of social action: A program for at-risk youth. Journal of the American Art Therapy Association, 22(1), 32-38. doi:10.1080/07421656.2005.10129459

Briks, A. (2007). Art therapy with adolescents. Canadian Art Therapy Association Journal, 20(1), 2-15. doi:10.1080/08322473.2007.11432288

Bstan-'dzin-rgya-mtsho, D. L. X., Tutu, D., \& Abrams, D. C. (2016). The book of joy: Lasting happiness in a changing world. New York: Avery.

Chilton, G., Gerber, N., Bechtel, A., Councill, T., Dreyer, M., \& Yingling, E. (2015). The art of positive emotions: Expressing positive emotions within 
the intersubjective art making process. Canadian Art Therapy Association Journal, 28(1), 12-25. doi:10.1080/08322473.2015.1100580

Clark, T. (2002). The prayer flag tradition. Radiant Heart Studio. Retrieved from http://www.prayerflags.com/download/article.pdf

Hocoy, D. (2005). Art therapy and social action: A transpersonal framework. Journal of the American Art Therapy Association, 22(1), 7-16. doi:10.1080/ 07421656.2005.10129466

Kaplan, F. F. (2007). Art therapy and social action. Philadelphia, PA: Jessica Kingsley Publishers.

Laffier, J. (2016). Empowering bullying victims through artistic expression. Canadian Art Therapy Association Journal, 29(1), 12-20. doi:10.1080/ $\underline{08322473.2016 .1171987}$

Lind, C., Cantell, M., Baggott, S., Houde, M., \& Coupal, S. (2015). Participatory action research with therapeutic arts practitioners: Research capacity building in a pediatric hospital. Canadian Art Therapy Association Journal, 28, 1-11. doi:10.1080/08322473.2015.1083642

Linton, J. (2017). A natural response to a natural disaster: The art of crisis in Nepal. Canadian Art Therapy Association Journal, 30, 31-40. doi:10.1080/ $\underline{08322473.2017 .1317201}$

Marcia, J., \& Josselson, R. (2013). Eriksonian personality research and its implications for psychotherapy. Journal of Personality, 81(6), 617-629. doi:10.1111/jopy.12014

May, R. (1975). The courage to create. New York, NY: W. W. Norton.

McIntosh, E. (2015). Why we need the arts: John Macmurray on education and the emotions. Educational Philosophy and Theory, 47(1), 47-60. doi:10.1080/00131857.2013.866533

Potash, J., \& Ho, R. (2011). Drawing involves caring: Fostering relationship building through art therapy for social change. Art Therapy: Journal of the American Art Therapy Association, 28(2), 74-81. doi:10.1080/ $\underline{07421656.2011 .578040}$

Rubin, J. A. (2005). Child art therapy: $25^{\text {th }}$ anniversary edition. Hoboken, NJ: John Wiley \& Sons, Inc.

Snir, S., \& Regev, D. (2014). Expanding art therapy process research through self-report questionnaires. Art Therapy: Journal of the American Art Therapy Association, 31(3), 131-136. doi:10.1080/07421656.2014.935588

Suffla, S., Seedat, M., \& Bawa, U. (2015). Reflexivity as enactment of critical community psychologies: Dilemmas of voice and positionality in a multi- 
country photovoice study. Journal of Community Psychology, 43(1), 9-2. doi:10.1002/jcop.21691

Thorp, C. L. (2017, April 24). Tibetan sand mandalas. Ancient History Encyclopedia. Retrieved from https://www.ancient.eu/article/1052/ tibetan-sand-mandalas/

Ueda, N. (2013). The Dalai Lama on what matters most: Conversations on anger, compassion, and action. Charlottesville, VA: Hampton Roads.

Warne, M., Snyder, K., \& Gadin, K. G. (2012). PhotoVoice: An opportunity and challenge for students' genuine participation. Health Promotion International, 28(3), 299-310. doi:10.1093/heapro/das011 